\section{6 "COMPREHENSIVE CARE MODEL" FOR DIABETES WITHIN A PRIMARY CARE CLINIC: PRE-VISIT PLANNING, AT-VISIT EFFICIENCY, AND INTER-VISIT CARE}

Jaishree Hariharan, Gary Fischer, Debbie Simak. University of Pittsburgh Medical Center, United States

\subsection{6/bmjqs-2015-IHlabstracts. 15}

Background UPP-GIM, a large urban academic primary-care practice and a patient-centered medical home, treats approximately 1800 diabetics. Despite multiple interventions, the number of patients with $\mathrm{A} 1 \mathrm{C}=9 \%$ remained at $14 \%$, and dilated retina exam (DRE) rate was only $64 \%$.

Objectives 1. Create a comprehensive team-based model that engages patients throughout their continuum of care, focusing on patients with $\mathrm{A} 1 \mathrm{C}=9 \%$.

2. Incrementally improve glycemic control, diabetes outcomes and DRE rate.

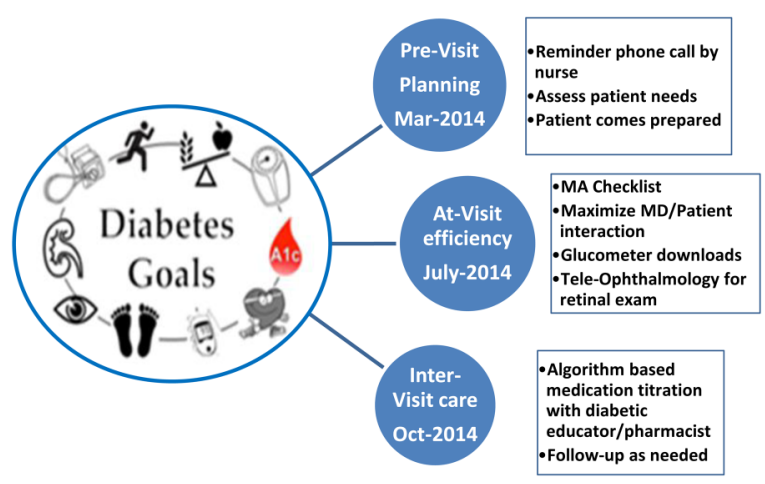

Figure 1 Comprehensive Care Model: Phases and Timeline.

\begin{tabular}{|l|l|l|l|}
\hline & $\begin{array}{l}\text { Diabetes } \\
\text { Registry * }\end{array}$ & $\begin{array}{l}\text { A1C } \geq 9 \% \\
\text { Cohort } \\
\text { (Intervention } \\
\text { Patients) }\end{array}$ & $\begin{array}{l}\text { A1C < 9\% } \\
\text { Usual care }\end{array}$ \\
\hline $\begin{array}{l}\text { \# Unique } \\
\text { patients } \\
\text { (Dec 2013) }\end{array}$ & 1704 & $\mathbf{2 4 6 ( 1 4 \% )}$ & $1458(86 \%)$ \\
\hline Female & $54 \%$ & $54 \%$ & $54 \%$ \\
\hline$<40$ & $7 \%$ & $16 \%$ & $5 \%$ \\
\hline $\mathbf{4 0 - 6 4}$ & $56 \%$ & $\mathbf{6 3 \%}$ & $55 \%$ \\
\hline$>65$ & $37 \%$ & $21 \%$ & $40 \%$ \\
\hline$<65$ & $63 \%$ & $79 \%$ & $60 \%$ \\
\hline $\begin{array}{l}\text { Black/African } \\
\text { American }\end{array}$ & $39 \%$ & $52 \%$ & $36 \%$ \\
\hline White & $57 \%$ & $46 \%$ & $59 \%$ \\
\hline $\begin{array}{l}\text { Mean A1C } \\
\text { (Dec 2013) }\end{array}$ & $7.5(( \pm 1.7)$ & $10.8(( \pm 1.7)$ & $6.9(( \pm 0.9)$ \\
\hline $\begin{array}{l}\text { Mean A1C } \\
\text { (June 2015) }\end{array}$ & $7.4(( \pm 1.7)$ & $\mathbf{9 . 5 ~ ( ( \pm 1 . 9 )}$ & $7.1( \pm 1.35)$ \\
\hline
\end{tabular}

* Patients with documented A1C in 2013

Figure 2 Patient characteristics.
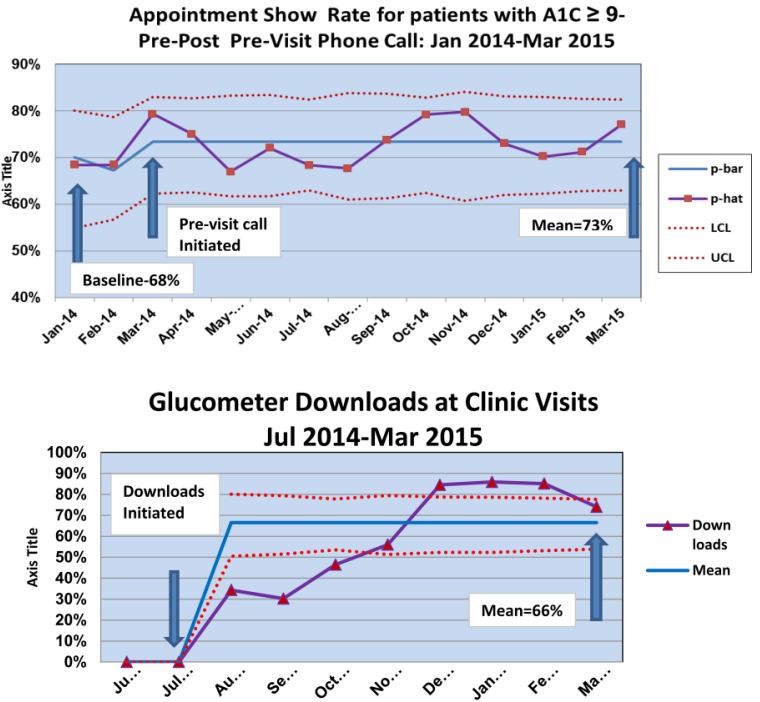

UPP-GIM Quarterly Report: All Diabetes Patients, A1C $\geq 9 \%$ Trends ( N 1850)

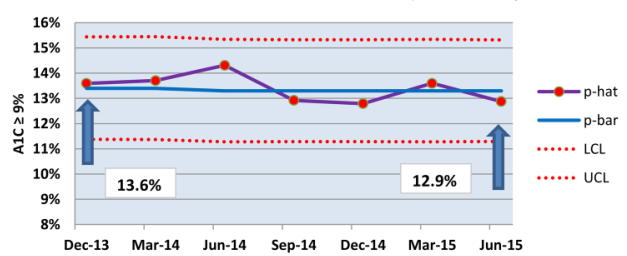

UPP-GIM Quarterly Report: All Diabetes Patients: Eye Exam Rates

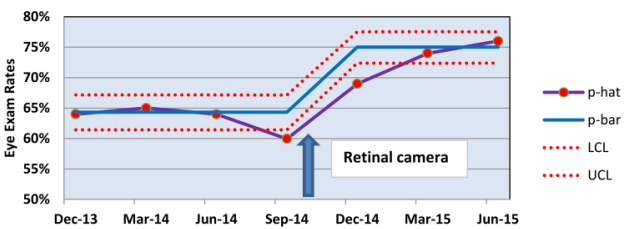

Figure 3 Control Charts showing results of Pre-Visit planning (PVP), Glucometer downloads (At-Visit), Trend of A1C $\geq 9 \%$, and eye exam rates in our diabetes population.

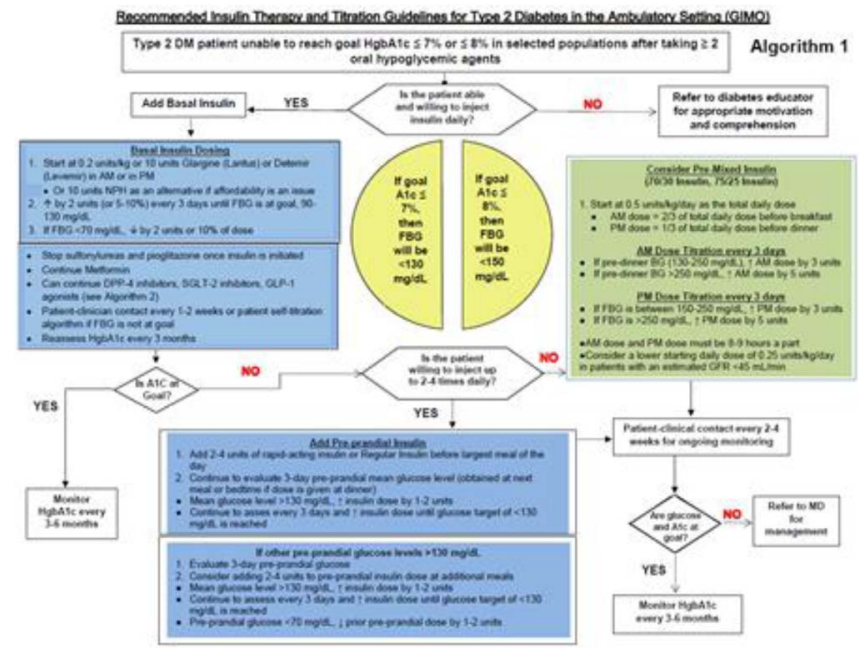

Figure 4 Insulin Titration Algorithm used by Diabetic educators for inter-visit care. 
Methods In January 2014, a multi-disciplinary diabetes team was created to redesign care. A comprehensive care model was established and implemented in phases. All clinic staff and physicians participated. It included engaging patients with a previsit phone call, improving at-visit efficiency to maximize addressing all patient needs, including downloading and printing glucose meter reports and adding tele-ophthalmology, and intensifying inter-visit care with algorithm-based medication titration. (see figure)

Processes and outcomes were tracked over 18 months. Control charts were used to evaluate processes and outcome measures as phases were implemented and quarterly reports for outcomes.

Results Mean A1C in the cohort of patients starting with $\mathrm{A} 1 \mathrm{C}=9 \%(\mathrm{n}=246)$ improved from $10.8( \pm 1.7)$ to $9.5( \pm 1.9)$. Appointment show rate improved from $68 \%$ to $73 \%$. Encounters with diabetic educators rose from 20\% to $54 \%$. Meter download compliance reached almost $90 \%$ and DRE rates improved from $64 \%$ to $76 \%$.

Conclusions Engaging uncontrolled diabetic patients before, during, and after visits with a team-based approach and novel day-of-visit efficiencies improved glycemic control and eye exam rates. Continued monitoring is needed to ensure the durability of these gains. 